\title{
Forecasting Motorcycle Sales Using Nearest Symmetric Trapezoidal Fuzzy Number
}

\author{
Jessica $^{1}$, Seng Hansun ${ }^{2}$ \\ Computer Science Department, Universitas Multimedia Nusantara, Tangerang, Indonesia ${ }^{1}$ susanto_jessica@ \\ yahoo.co.id, ${ }^{2}$ hansun@umn.ac.id \\ Submitted $11^{\text {th }}$ October 2016 \\ Approved $10^{\text {th }}$ December 2016
}

\begin{abstract}
A business activity aimed at obtaining profits, relies on the sales of existing products. Sales forecasting as an initial step in planning activities helps provide an overview of sales in a business for the coming period based on data available. This research aims to design and develop a motorcycle sales forecasting application using Fuzzy Time Series with Nearest Symmetric Trapezoidal Fuzzy Number approach to predict the next period sales of PT Mutiara Motor. To test the accuracy of the method used in application, we used the MSE and MAPE criteria. Based on the results of three experiments taken: (1) monthly 'All Category'-'All Type' with MSE $=\mathbf{5 4 . 4 2}$ and $\mathrm{MAPE}=\mathbf{4 . 2 8 \%}$, (2) monthly 'Beat CW Fuel Injection' with $\mathrm{MSE}=3.67$ and $M A P E=4.04 \%$, and (3) daily 'All Category''All Type' with MSE $=1.42$ and MAPE $=\mathbf{2 7 . 3 6 \%}$ we indicate that Fuzzy Time Series with Nearest Symmetric Trapezoidal Fuzzy Number approach could give higher accuracy than the Single Exponential Smoothing method as comparison in forecasting motorcycle sales.
\end{abstract}

Index Terms-fuzzytimeseries, nearest symmetric trapezoidal fuzzy number, sales forecasting

\section{Introduction}

A business activity aimed at obtaining profits relies on the sales of existing products. However, companies often have problems in determining what inventory should be held for get maximum sales, achieve targets, and in accordance with market needs. Inventory that are not well planned can result in the accumulation of goods in the warehouse which then reduces the company's profits, even causing losses that incurred due to procurement of goods exceeds the results obtained from the sales [1].
Sales forecast is the first step of a variety of plans that can be performed by a company. PT Mutiara Motor is a business that is engaged in the sales of Honda motorcycles. Companies often experience difficulties in implementing the appropriate inventory planning and sales that according to market needs, which resulting in the accumulation or shortages of stock that reduce company profits. Therefore, the leaders of the company, in this case the managers require a computerized application that can help to see and predict the level of sales that exist in the company efficiently in order to plan accordingly.

Forecasting method chosen to develop applications in this research is the fuzzy time series with Nearest Symmetric Trapezoidal Fuzzy Numbers (NSTFN) approach which is part of the modern time series methods $[2,3]$.

Fuzzy time series in implementation as method of forecasting has been proven that the prediction results are very accurate indicated by the small value of the forecasting error measurement [4 6]. There are even some derivative works on fuzzy time series which had been done [7 - 10]. The use of fuzzy number can overcome the problems of conventional fuzzy time series related to give the results in the form of trapezoidal fuzzy number using $\alpha$-cut principles instead of a single value [11]. Nearest symmetric trapezoidal fuzzy number is said to be able to overcome the problem of defuzzification, loss of too much information [12].

The use of fuzzy time series with Nearest Symmetric Trapezoidal Fuzzy Number approach in this study provide new insights for the application of these methods in sales forecasting of motorcycles. With a variety of 
existing forecasting methods, the selection of a good method will improve the accuracy of forecasting results as measured by indicators such as Mean Square Error (MSE) and Mean Absolute Percentage Error (MAPE), so it is necessary to study the accuracy and reliability of the methods used to forecast.

II. Fuzzy Time Series - Nearest Symmetric Trapezoidal Fuzzy Number

Fuzzy time series with Nearest Symmetric Trapezoidal Fuzzy Number approach is a forecasting method developed by Rajaram and Vamitha in a research journal published on 2012 [12], which is the development of fuzzy time series introduced by Chen [13].

The use of fuzzy number can overcome the problems of conventional fuzzy time series related to give the results in the form of trapezoidal fuzzy number instead of a single value, so that the decision maker gets wider picture when making a forecast or a plan. Furthermore, with the Nearest Symmetric Trapezoidal Fuzzy Number, we can defuzzification the fuzzy number and get the fuzziness of the original value.

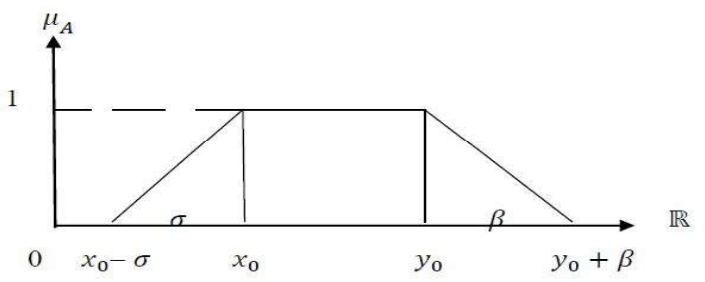

Fig. 1. Trapezoidal Fuzzy Number $\left(\mathrm{x}_{0}, \mathrm{y}_{0}, \sigma, \beta\right)$

[12]

Fuzzy Time Series with Nearest Symmetric Trapezoidal Fuzzy Number approach consists of the following steps [12]:

1. Collect the historical data $\mathrm{Av}_{\mathrm{t}}$.

2. Find the maximum $D_{\max }$ and the minimum $\mathrm{D}_{\min }$ among all $\mathrm{Av}_{\mathrm{t}}$ To form the universe of discourse, two small numbers $\mathrm{D}_{1}$ and $\mathrm{D}_{2}$ are assigned. Define the universe of discourse as

$\mathrm{U}=\left[\mathrm{D}_{\min }-\mathrm{D}_{1}, \mathrm{D}_{\max }+\mathrm{D}_{2}\right]$

(1)

3. Divide the universe into seven equal length intervals $U_{i}$ where $i=1$ to 7 . According the distribution of the historical data, divide Ui into intervals of different length and denotes $\mathrm{v}_{\mathrm{j}}$.

4. According to the intervals $\mathrm{v}_{1}=\left[\mathrm{d}_{1}, \mathrm{~d}_{2}\right], \mathrm{v}_{2}=$ $\left[\mathrm{d}_{2}, \mathrm{~d}_{3}\right], \ldots, \mathrm{v}_{\mathrm{m}}=\left[\mathrm{d}_{\mathrm{m}, \mathrm{d}+1} \mathrm{~d}_{\mathrm{m}+1}\right]$ derived in step 3 , the fuzzy sets is define on trapezoidal fuzzy numbers.

5. If the value of the historical data is located in the range of $\mathrm{v}_{\mathrm{i}}$, then it belongs to the fuzzy number $A_{j}$. All the data must be classified into the corresponding fuzzy numbers.

6. Derive the fuzzy logical relationships based on definition:

Suppose $F(t-1)=A_{i}$ and $F(t)=A_{j}$ a fuzzy logical relationship can be derived as $A_{i} \rightarrow A_{j}$ where $A_{i}$ and $A_{j}$ are called the left hand side and the right hand side of the fuzzy logical relationship respectively.

7. Arrange the fuzzy logical relationships into the fuzzy logical relationship groups based on the same fuzzy number on the left hand sides of the fuzzy logical relationships. If the transition happens to the same fuzzy set, make a separate logical relationship group.

8. The forecasted value at time $t, \mathrm{Fv}_{\mathrm{t}}$ is determined by the following three heuristic rules. Assume the fuzzy number $\mathrm{Av}_{\mathrm{t}}$ at time $\mathrm{t}-1$ is $\mathrm{A}_{\mathrm{j}}$

Rule 1: If the fuzzy logical relationship group of $A_{j}$ is empty, $\mathrm{Aj}_{\mathrm{j}} \rightarrow$ o or $\mathrm{A}_{\mathrm{j}} \rightarrow \mathrm{A}_{\mathrm{j}}$ then the forecasted value $\mathrm{Fv}_{\mathrm{t}}$ is $\mathrm{R}\left[\mathrm{NSTFN}\left(\mathrm{A}_{\mathrm{j}}\right)\right]$.

Rule 2: If the fuzzy logical relationship group of $A_{j}$ is one to one, i.e., $A_{j} \rightarrow A_{k}$ then the forecasted value $\mathrm{Fv}_{\mathrm{t}}$ is $\mathrm{R}\left[\operatorname{NSTFN}\left(\mathrm{A}_{\mathrm{k}}\right)\right]$.

Rule 3: If the fuzzy logical relationship group of $A_{j}$ is one to many, i.e., $A_{j} \rightarrow A_{k 1}, A j$ $\rightarrow A_{k 2, \ldots,} A_{j} \rightarrow A_{k p}$ then the forecasted value $\mathrm{Fv}_{\mathrm{t}}$ is calculated as.

(2)

$\boldsymbol{F}_{t}=R\left[\frac{\operatorname{NSTFN}\left(A_{k 1}\right)+\operatorname{NSTFN}\left(A_{k 2}\right)+\ldots+\operatorname{NSTFN}\left(A_{b}\right)}{p}\right]$

For that rules, this following formulas are applied:

a. For the trapezoidal fuzzy number $A=\left(t_{1}, t_{2}, t_{3}\right.$, $t_{4}$ ) where $\left[t_{2}, t_{3}\right]$ is core of $A, t_{1}$ is left width and $t_{4}$ is right width, then the nearest symmetric

\section{ULTIMATICS, Vol. VIII, No. 2 | Desember 2016}


trapezoidal fuzzy number for A is.

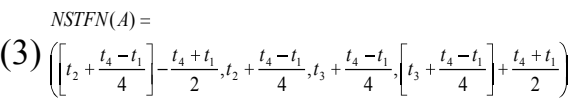

b.

(4)

$$
R(A)=\frac{a+b+c+d}{4}
$$

where $A=(a, b, c, d)$.

By utilizing the trapezoidal fuzzy number and $\alpha$-cut principles of fuzzy number, then the possible forecasted interval can be obtained where $\alpha$ as degree of confidence is $0 \leq \alpha \leq 1$.

Interval forecast $\left[F_{L}, F_{U}\right]$ which is lower limit and upper limit of interval respectively, is obtained by [14],

$$
\alpha=\left(F_{L}-d_{m-1}\right) /\left(d_{m-} d_{m-1}\right)
$$

and

$$
\alpha=\left(d_{m+2}-F_{U}\right) /\left(d_{m+2-} d_{m+1}\right)
$$

\section{Forecast Error Measurement}

After doing the forecasting, it is necessary to measure the accuracy of forecasting methods because errors may occur. Forecasting error is the difference between the forecasted data with the actual data. There are several methods to measure forecast error, such as Mean Square Error (MSE) and Mean Absolute Percentage Error (MAPE).

\section{A. Mean Square Error (MSE)}

Mean Square Error (MSE) denotes the average of the square of error sum between the forecasted data and the actual data. The formula can be written as follows [15],

$$
M S E=\frac{\sum_{t=1}^{n}\left(X_{t}-F_{t}\right)^{2}}{n}
$$

where $n$ denotes the number of data, $X_{t}$ is the actual data and $F_{t}$ is the forecasted data.

\section{B. Mean Absolute Percentage Error (MAPE)}

Mean Absolute Percentage Error (MAPE) value gives us an indication about how much the average of absolute error of the forecasted data compare to the actual data, and denotes by the formula [15],

$$
M A P E=\left(\frac{100}{n}\right) \sum_{t=1}^{n}\left|\frac{X_{t}-F_{t}}{X_{t}}\right|
$$

where $n$ denotes the number of data, $X_{t}$ is the actual data and $F_{t}$ is the forecasted data.

\section{Implementation and Results}

Fuzzy Time Series Method with Nearest Symmetric Trapezoidal Fuzzy Number approach is used on Forecasting page at the application and used to perform sales forecasting of motorcycles. Fig. 2 and Fig. 3 show the forecasting process flowchart and Fuzzy Time Series-Nearest Symmetric Trapezoidal Fuzzy Number flowchart consecutively.

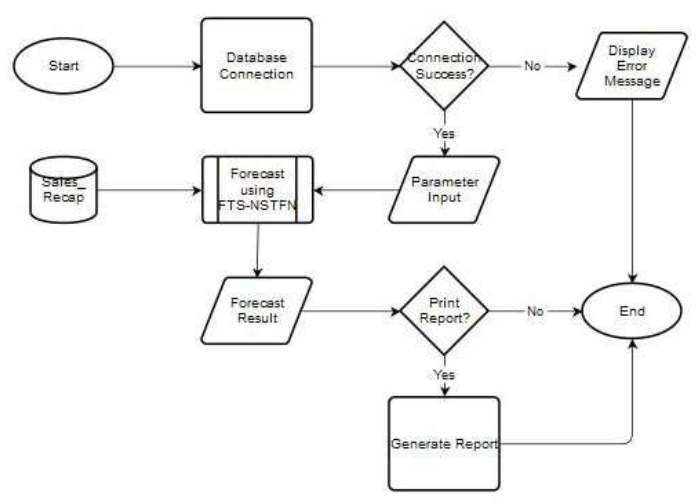

Fig. 2. Forecasting Flowchart 


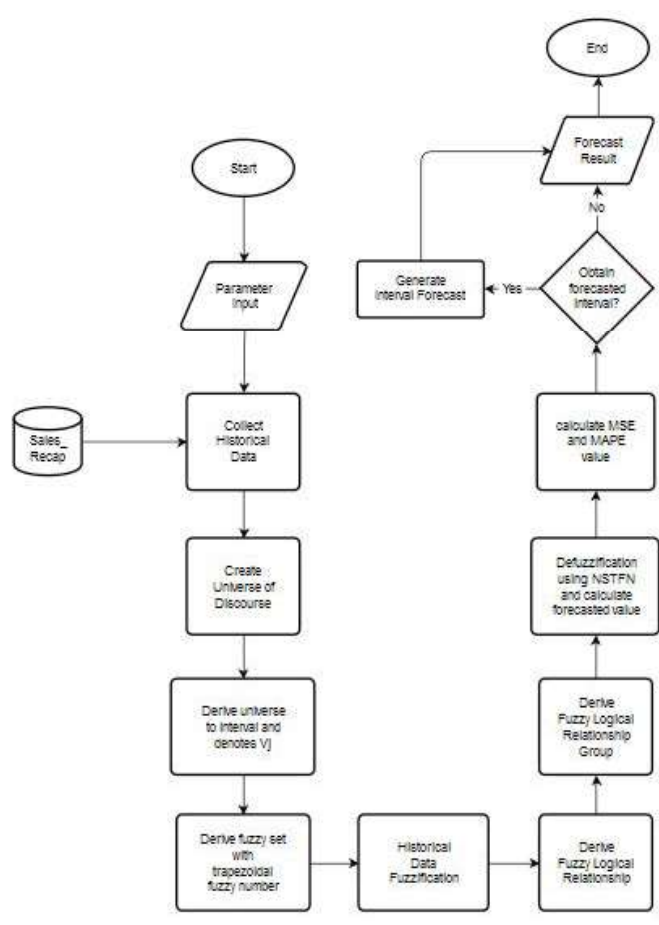

Fig. 3. Fuzzy Time Series-Nearest Symmetric Trapezoidal Fuzzy Number Flowchart

In the forecasting page, managers are asked to fill in the parameters required to perform forecasting, which is the product that will be predicted by category and by product name. If no change of selection, sales forecasting will include all categories and all products, by default.

There are two sales forecasting period, i.e., daily and monthly that can be chosen. Default mode is monthly. Daily mode is an additional feature to make sales forecasting more frequently and only for 'All Category'-'All Type'. Managers will enter a period of historical data that will be used in the form of start month and year, as well as end month and year in monthly mode. The start date and end date is used if it is in the daily mode.

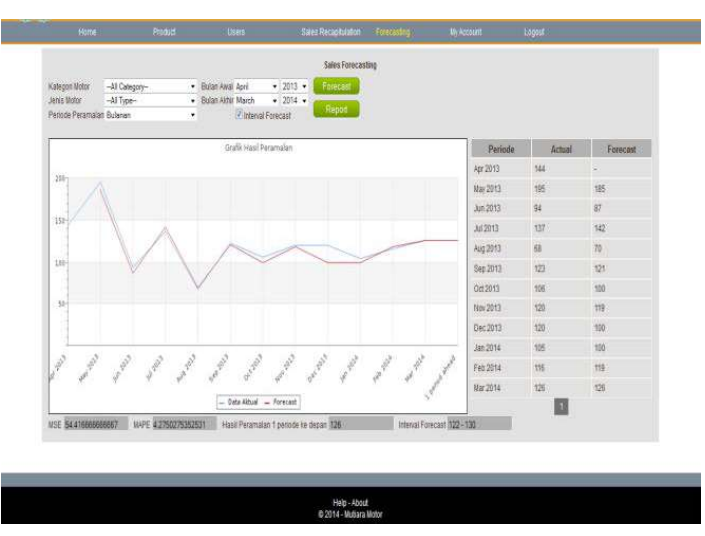

Fig. 4. The Interface of Forecasting Page

The experiment for forecasting, with sample data 'All Category'-'All Type' and the number of data been used were 12 sales data, which has been taken monthly from April 2013 to March 2014 as follows.

a. From the collection of historical data, minimum value $\mathrm{D}_{\min }=68$ and the maximum value $\mathrm{D}_{\text {max }}=$ 195 is known. To make calculation easier, $D_{1}$ and $\mathrm{D}_{2}$ used.

In general, the selection of $\mathrm{D}_{1}$ and $\mathrm{D}_{2}$ is random, but in this research, the selection is done by setting $\mathrm{D}_{\min }-\mathrm{D}_{1}$ by rounding down to the nearest for Dmin and $D_{\max }+D_{2}$ by rounding up to the nearest for $\mathrm{D}_{\max }$, so the universe of discourse is set as follows. $U=[60,200]$.

b. Divide $U$ into seven intervals, $U_{\mathrm{i}} \mathrm{i}=1$ to 7 with equal length is described in Table 1.

Table 1. Partition of the Universe of Discourse

\begin{tabular}{|c|c|}
\hline Ui & Interval \\
\hline $\mathrm{U}_{1}$ & {$[60,80)$} \\
$\mathrm{U}_{2}$ & {$[80,100)$} \\
$\mathrm{U}_{3}$ & {$[100,120)$} \\
$\mathrm{U}_{4}$ & {$[120,140)$} \\
$\mathrm{U}_{5}$ & {$[140,160)$} \\
$\mathrm{U}_{6}$ & {$[160,180)$} \\
$\mathrm{U}_{7}$ & {$[180,200)$} \\
\hline \multicolumn{2}{|c|}{ By the following frequency distribution, }
\end{tabular}

Table 2. Frequency Distribution

\begin{tabular}{|l|l|l|l|l|l|l|l|}
\hline Interval & $\mathrm{U}_{1}$ & $\mathrm{U}_{2}$ & $\mathrm{U}_{3}$ & $\mathrm{U}_{4}$ & $\mathrm{U}_{5}$ & $\mathrm{U}_{6}$ & $\mathrm{U}_{7}$ \\
\hline Frequency & 1 & 1 & 3 & 5 & 1 & 0 & 1 \\
\hline
\end{tabular}


ISSN 2085-4552

divide the intervals $U$ to $U_{\text {as }}$ as described in Table 3. From the frequency distribution of the

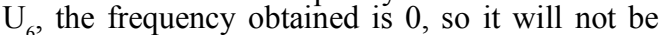
included to determine $\mathrm{v}_{\mathrm{j}}$.

Table 3. Partition of V

\begin{tabular}{|c|c|}
\hline $\mathbf{V j}$ & Interval \\
\hline $\mathrm{V}_{1}$ & {$[60,80)$} \\
\hline $\mathrm{V}_{2}$ & {$[80,100)$} \\
\hline $\mathrm{V}_{3}$ & {$[100,107)$} \\
\hline $\mathrm{V}_{4}$ & {$[107,113)$} \\
\hline $\mathrm{V}_{5}$ & {$[113,120)$} \\
\hline $\mathrm{V}_{6}$ & {$[120,124)$} \\
\hline $\mathrm{V}_{7}$ & {$[124,128)$} \\
\hline $\mathrm{V}_{8}$ & {$[128,132)$} \\
\hline $\mathrm{V}_{9}$ & {$[132,136)$} \\
\hline $\mathrm{V}_{10}$ & {$[136,140)$} \\
\hline $\mathrm{V}_{11}$ & {$[140,160)$} \\
\hline $\mathrm{V} 12_{12}$ & {$[180,200)$} \\
\hline
\end{tabular}

a. The trapezoidal fuzzy numbers can be then defined by,

Table 4. Trapezoidal Fuzzy Number

\begin{tabular}{|c|c|}
\hline $\mathbf{A}_{\mathbf{i}}$ & Interval \\
\hline $\mathrm{A}_{1}$ & {$[40,60,80,100]$} \\
\hline $\mathrm{A}_{2}$ & {$[60,80,100,107]$} \\
\hline $\mathrm{A}_{3}$ & {$[80,100,107,113]$} \\
\hline $\mathrm{A}_{4}$ & {$[100,107,113,120]$} \\
\hline $\mathrm{A}_{5}$ & {$[107,113,120,124]$} \\
\hline $\mathrm{A}_{6}$ & {$[113,120,124,128]$} \\
\hline $\mathrm{A}_{7}$ & {$[120,124,128,132]$} \\
\hline $\mathrm{A}_{8}$ & {$[124,128,132,136]$} \\
\hline $\mathrm{A}_{9}$ & {$[128,132,136,140]$} \\
\hline $\mathrm{A}_{10}$ & {$[132,136,140,160]$} \\
\hline $\mathrm{A}_{11}$ & {$[136,140,160,200]$} \\
\hline $\mathrm{A}_{12}$ & {$[140,160,200,240]$} \\
\hline
\end{tabular}

b. The next step is to fuzzify the historical data as shown in Table 5.

Table 5. Fuzzification

\begin{tabular}{|l|c|c|}
\hline Period & Actual Data & Fuzzification \\
\hline April 2013 & 144 & $\mathrm{~A}_{11}$ \\
\hline May 2013 & 195 & $\mathrm{~A}_{12}$ \\
\hline June 2013 & 94 & $\mathrm{~A}_{2}$ \\
\hline July 2013 & 137 & $\mathrm{~A}_{10}$ \\
\hline August 2013 & 68 & $\mathrm{~A}_{1}$ \\
\hline September 2013 & 123 & $\mathrm{~A}_{6}$ \\
\hline
\end{tabular}

\begin{tabular}{|l|l|l|}
\hline October 2013 & 106 & $\mathrm{~A}_{3}$ \\
\hline November 2013 & 120 & $\mathrm{~A}_{6}$ \\
\hline December 2013 & 120 & $\mathrm{~A}_{6}$ \\
\hline January 2014 & 105 & $\mathrm{~A}_{3}$ \\
\hline February 2014 & 116 & $\mathrm{~A}_{5}$ \\
\hline March 2014 & 126 & $\mathrm{~A}_{7}$ \\
\hline
\end{tabular}

c. According to the fuzzified historical data, the fuzzy logical relationships are derived as follows.
$\mathrm{A}_{11} \rightarrow \mathrm{A}_{12}$
$\mathrm{A}_{12} \rightarrow \mathrm{A}_{2}$
$\mathrm{A}_{2} \rightarrow \mathrm{A}_{10}$
$\mathrm{A}_{1} \rightarrow \mathrm{A}_{6}$
$\mathrm{A}_{10} \rightarrow \mathrm{A}$
$\mathrm{A}_{6} \rightarrow \mathrm{A}_{3}$
$\mathrm{A}_{3} \rightarrow \mathrm{A}_{6} \quad \mathrm{~A}_{6} \rightarrow \mathrm{A}_{6}$
$\mathrm{A}_{6} \rightarrow \mathrm{A}_{3}$
$\mathrm{A}_{3} \rightarrow \mathrm{A}_{5} \quad \mathrm{~A}_{5} \rightarrow \mathrm{A}_{7}$

d. Generate the fuzzy logical relationship groups as follows.
$\mathrm{A}_{11} \rightarrow \mathrm{A}_{12}$
$\mathrm{A}_{12} \rightarrow \mathrm{A}_{2}$
$\mathrm{A}_{2} \rightarrow \mathrm{A}_{10}$
$\mathrm{A}_{10} \rightarrow \mathrm{A}_{1}$
$\mathrm{A}_{1} \rightarrow \mathrm{A}_{6}$
$\mathrm{A}_{6} \rightarrow \mathrm{A}_{3}$
$\underset{\mathrm{A}_{5}}{\stackrel{\mathrm{A}_{3}}{\rightarrow} \mathrm{A}_{7}} \rightarrow \mathrm{A}_{6}, \mathrm{~A}_{5}$
$\mathrm{A}_{6} \rightarrow \mathrm{A}_{6}$

e. According to three heuristic rules to calculate forecasted data, therefore defuzzification to get forecasted data for April 2014 described as follows.

Fuzzified historical data for March 2014 is A and the corresponding fuzzy logical relationship group is empty $\left(A_{j} \rightarrow \varphi\right)$.

$A_{7}=[120,124,128,132]$, with formula

$\operatorname{NSTFN}(A)=$
$\left(\left[t_{2}+\frac{t_{4}-t_{1}}{4}\right]-\frac{t_{4}+t_{1}}{2}, t_{2}+\frac{t_{4}-t_{1}}{4}, t_{3}+\frac{t_{4}-t_{1}}{4},\left[t_{3}+\frac{t_{4}-t_{1}}{4}\right]+\frac{t_{4}+t_{1}}{2}\right)$

therefore,

$\mathrm{t}_{1}=124-120=4$ and $\mathrm{t}_{4}=132-128=4$

$$
\begin{gathered}
\frac{t_{4}-t_{1}}{4}=\frac{4-4}{4}=0 \quad \frac{t_{4}+t_{1}}{2}=\frac{4+4}{2}=4 \\
\operatorname{NSTFN}\left(\mathrm{A}_{7}\right)=[120,124,128,132] \\
R\left(\operatorname{NSTFN}\left(A_{4}\right)=\frac{120+124+128+132}{4}=126,\right.
\end{gathered}
$$


so according to the first rule, the Fv for April 2014 is 126 units for sales of 'All Category'-All Type'.

According to manager of this company, the confidence level of forecasted data is $60 \%$, therefore the forecasted interval with $60 \%$ confidence level is given by,

$$
\begin{aligned}
& 1-\alpha=0.6 \text { and } \alpha=0.4 \\
& \alpha=\left(F_{L}-d_{m-1}\right) /\left(d_{m-} d_{m-1}\right) \\
& \alpha=\left(d_{m+2}-F_{R}\right) /\left(d_{m+2-} d_{m+1}\right) \\
& 0.4=\mathrm{F}_{\mathrm{L}}-120 /(124-120), \mathrm{F}_{\mathrm{L}}=121.6 \approx 122
\end{aligned}
$$

$$
\begin{aligned}
& 0.4=\left(132-\mathrm{F}_{\mathrm{R}}\right) /(132-128), \mathrm{F}_{\mathrm{R}}=130.4 \approx 130 \\
& {\left[\mathrm{~F}_{\mathrm{L}}, \mathrm{F}_{\mathrm{R}}\right]=[122,130]} \\
& \text { or can be expressed sales forecast for the month of }
\end{aligned}
$$
April 2014 was between 122 units and 130 units.

Forecasted data and the MSE and MAPE generated by Fuzzy Time Series with Nearest Symmetric Trapezoidal Fuzzy Numbers approach is described in Table 6.

Table 6. Forecasting Results

\begin{tabular}{|l|c|c|c|c|}
\hline \multicolumn{1}{|c|}{ Period } & Actual Data & Forecast & $\left(X_{t}-F_{t}\right)^{2}$ & $\left|\frac{X_{t}-F_{t}}{X_{t}}\right|$ \\
\hline April 2013 & 144 & - & - & - \\
\hline May 2013 & 195 & 185 & 100 & 0.051282051 \\
\hline June 2013 & 94 & 87 & 49 & 0.074468085 \\
\hline July 2013 & 137 & 142 & 25 & 0.03649635 \\
\hline August 2013 & 68 & 70 & 4 & 0.029411765 \\
\hline September 2013 & 123 & 121 & 4 & 0.016260163 \\
\hline October 2013 & 106 & 100 & 36 & 0.056603774 \\
\hline November 2013 & 120 & 119 & 1 & 0.008333333 \\
\hline December 2013 & 120 & 100 & 400 & 0.166666667 \\
\hline January 2014 & 105 & 100 & 25 & 0.047619048 \\
\hline February 2014 & 116 & 119 & 9 & 0.025862069 \\
\hline March 2014 & 126 & 126 & 0 & 0 \\
\hline
\end{tabular}

After three experiments, (1) 'All Category' 'All Type' monthly, (2) 'Scooter' - 'Beat CW Fuel Injection' monthly, (3) 'All Category' - 'All Type' daily, each using 12 historical sales data, to test the accuracy of the method of Fuzzy Time Series with Nearest Symmetric Trapezoidal Fuzzy Numbers approach compare with the conventional method, which in this study were compared with the Single Exponential Smoothing method. From the experiments taken, the results are as follows. 
Table 7. Forecast Experiments Recapitulation

\begin{tabular}{|c|c|c|c|c|c|c|}
\hline \multirow[t]{2}{*}{$\begin{array}{l}\text { Forecast } \\
\text { Target }\end{array}$} & \multirow[t]{2}{*}{$\begin{array}{l}\text { Mode } \\
\text { (Period) }\end{array}$} & \multirow{2}{*}{$\begin{array}{c}\text { Number } \\
\text { of Historical } \\
\text { Data }\end{array}$} & \multicolumn{2}{|c|}{$\begin{array}{c}\text { Fuzzy Time Series- } \\
\text { NSTFN }\end{array}$} & \multicolumn{2}{|c|}{$\begin{array}{l}\text { Single Exponential } \\
\text { Smoothing }\end{array}$} \\
\hline & & & MSE & MAPE & MSE & MAPE \\
\hline \multirow{2}{*}{$\begin{array}{l}\text { All Category/ } \\
\text { All Type }\end{array}$} & \multirow[t]{2}{*}{ Monthly } & \multirow[t]{2}{*}{12} & \multirow[t]{2}{*}{54.42} & \multirow[t]{2}{*}{$4.28 \%$} & 1020.92 & $20.53 \%$ \\
\hline & & & & & \multicolumn{2}{|c|}{$\alpha=0.2$} \\
\hline \multirow{2}{*}{$\begin{array}{c}\text { Scooter/ } \\
\text { Beat CW Fuel } \\
\text { Injection }\end{array}$} & \multirow[t]{2}{*}{ Monthly } & \multirow[t]{2}{*}{12} & \multirow[t]{2}{*}{3.67} & \multirow[t]{2}{*}{$4.04 \%$} & 194.17 & $31.12 \%$ \\
\hline & & & & & \multicolumn{2}{|c|}{$\alpha=0.4$} \\
\hline \multirow{2}{*}{$\begin{array}{l}\text { All Category/ } \\
\text { All Type }\end{array}$} & \multirow[t]{2}{*}{ Daily } & \multirow[t]{2}{*}{12} & \multirow[t]{2}{*}{1.42} & \multirow[t]{2}{*}{$27.36 \%$} & 1.92 & $26.94 \%$ \\
\hline & & & & & \multicolumn{2}{|c|}{$\alpha=0.5$} \\
\hline
\end{tabular}

From the table, it can be seen that the Fuzzy Time Series with Nearest Symmetric Trapezoidal Fuzzy Numbers approach gives higher accuracy than the single exponential smoothing based on the MSE and MAPE.

\section{CONCLUSION}

After the design and development of motorcycle sales forecasting application using Fuzzy Time Series with Nearest Symmetric Trapezoidal Fuzzy Number approach, the purpose of this research has been achieved. Based on the results of three experiments taken: (1) monthly 'All Category'-' All Type' with MSE $=54.42$ and MAPE $=4.28 \%$, (2) monthly Beat $\mathrm{CW}$ Fuel Injection with MSE $=3.67$ and MAPE $=4.04 \%$ and (3) daily 'All Category'-' All Type' with $\mathrm{MSE}=1.42$ and $\mathrm{MAPE}=27.36 \%$, we could indicate that this method gives higher accuracy than the Single Exponential Smoothing method.

The development of this research is still wide open. Some of the suggestions on this research are:

1. Comparison with other methods for forecasting using the same research data to get a more accurate forecasting result by comparing the forecast error.

2. Implementing a method that maximizes the performance of Universe of Discourse partition on Fuzzy time series, so it becomes more optimal and can recognize a better patterns from the historical data, i.e., by using genetic algorithms.

3. Factors affecting the sales need to be considered in order to provide a more accurate forecasting result, such as the influence of new products to old products or other variables.

\section{REFERENCES}

[1] D. Rosida, Pembangunan Perangkat Lunak Peramalan Penjualan dan Perencanaan Pemesanan untuk Membant Manajemen Persediaan pada Perusahaan Dagang, Final Project, Institut Teknologi Bandung, Bandung, 2008.

[2] C. Veeramani, C. Duraisamy, M. Sumathi, "Nearest Symmetric Trapezoidal Fuzzy Number Approximation Preserving Expected Interval", International Journal of Uncertainty, Fuzziness and Knowledge-Based System, 21 (05), 2013, DOI: 10.1142/S0218488513500372.

[3] B. Asady, "Trapezoidal Approximation of a Fuzzy Number Preserving the Expected Interval and Including the Core", American Journal of Operations Research, 3, 2013, pp.299306.

[4] A.D. Purwanto, C. Dewi, N.Y. Setiawan, "Penerapan Metode Fuzzy Time Series Average-Based pada Peramalan Data Harian Penampungan Susu Sapi”, Repositori Jurnal Mahasiswa PTIIK UB, 1(5), 2013.

[5] S. Hansun, "Peramalan Data IHSG Menggunakan Fuzzy Time Series", Indonesian Journal of Computing and Cybernetic System (IJCCS), 6 (2), 2012.

[6] S. Hansun, "Jakarta Stock Exchange (JKSE) Forecasting using Fuzzy Time Series", in Proceedings of 2013 International Conference on Robotics, Biomimetics, Intelligent Computational Systems (ROBIONETICS), 25-27 November 2013, Yogyakarta, Indonesia.

[7] Z. Ismail, R. Efendi, "Enrollment Forecasting Based on Modified Weight Fuzzy Time Series", Journal of Artificial Intelligence, 4 (1), 2011, pp.110-118.

[8] M.H. Lee, M.E. Nor, Suhartono, H.J. Sadaei, N.H.A Rahman, N.A.B. Kamisan, "Fuzzy Time Series: An Application to Tourism Demand Forecasting", American Journal of Applied Sciences, 9 (1), 2012, pp.132-140.

[9] E. Egrioglu, Y. Aslan, C.H. Aladag, "A New Fuzzy Time Series Method Based on Artificial Bee Colony Algorithm", Turkish Journal of Fuzzy Systems, 5 (1), 2014, pp.59-77. 
[10] E. Egrioglu, U. Yolcu, C.H. Aladag, C. Kocak, "An ARMA Type Fuzzy Time Series Forecasting Method Based on Particle Swarm Optimization", Mathematical Problems in Engineering, 2013, DOI: http://dx.doi. org/10.1155/2013/935815.

[11] H.T. Liu, "An Improved Fuzzy Time Series Forecasting Method Using Trapezoidal Fuzzy Numbers", Fuzzy Optimization and Decision Making, 6 (1), 2007, pp.63-80.

[12] S. Rajaram, V. Vamitha, "A Modified Approach on Fuzzy Time Series Forecasting", Annals of Pure and Applied Mathematics, 2 (1), 2012, pp.96-106.

[13] S.M. Chen, "Forecasting Enrollments Based on Fuzzy Time Series", Fuzzy Sets and Systems 81, 1996, pp.311-319.

[14] O. Duru, S. Yoshida, "Comparative Analysis of Fuzzy Time Series and Judgemental Forecasting: An Empirical Study of Forecasting Dry Bulk Shipping Index", International Symposium on Forecasting, 2009.

[15] K.D. Lawrence, R.K. Klimberg, S.M. Lawrence, Fundamentals of Forecasting using Excel, Industrial Press, Inc., New York, 2009. 